\title{
Drug costs of patients admitted to a government hospital; share of public and private expenditure
}

\author{
Wagachchi WP ${ }^{1}$, Wijekoon WMCD ${ }^{2}$, Kommalage $M^{2}$ \\ ${ }^{1}$ Nursing degree program, Faculty of Medicine, University of Ruhuna, Galle, Sri Lanka. \\ ${ }^{2}$ Department of Physiology, Faculty of Medicine, University of Ruhuna, Galle, Sri Lanka. \\ Correspondence: Prof. Mahinda Kommalage \\ e-mail: mahinda1@gmail.com \\ (D) https://orcid.org/0000-0002-2968-4341
}

\begin{abstract}
Introduction: Government hospitals are expected to provide free health service which includes drugs for in-patients. However, in practice, in-patients have to purchase drugs from outside when they are treated in government hospitals. The objective of the study was to investigate the drug expenditure of patients during their stay in government hospitals.
\end{abstract}

Methods: Cost incurred by 189 patients who were treated in a pediatric unit, a medical unit and a surgical unit in Teaching Hospital, Karapitiya for 3 - 10 days were studied. Details of drug cost incurred by patients were collected by interviewing patients, from BHTs, the hospital pharmacy and private pharmacies. Data were collected in two phases - from May to June and October to November in 2015.

Results: The average cost for drugs for a patient was Rs. 1,406.00, Rs. 3,204.00, Rs. 3,678.00 and from government per a patient was Rs. 548.00 , Rs. 1,239.00, Rs. 885.00 in pediatric, medical and surgical units respectively. Private expenditure on drugs is significantly higher than that from the government expenditure in all units. The highest percentage was spent for antibiotics both by the government (74\%) and by the patients (67.5\%). The highest antibiotic cost was recorded in the surgical unit. Surgical unit shows the highest per day difference of expenditure on drug by government and by patient. This difference widened with the number of hospitalised days.

Conclusions: Study shows that patients spent more than the government on drugs and the highest fraction of this is for antibiotics. The highest burden is reported among patients admitted to the surgical unit.

Keywords: Drug cost, in-patient, government hospital

\section{Introduction}

The Sri Lankan government takes considerable effort to finance and strengthen the healthcare services to ensure the efficient delivery of free health care to its citizens. Compared to other South Asian countries, Sri Lankan government spends more from country's total expenditure on the development of health sector (1). Expenditure for health is about $4 \%$ of the gross domestic product (GDP) of Sri Lanka (2).
Annual government expenditure on health is around 216 billion according to the budgetary allocation in 2016 (3). Majority of government expenditure is spent on maintaining public health delivery system island-wide. In-patient care is mainly funded by the government and about $75 \%$ of total national health expenditure is spent on in-patient care (1). 
Even though the government provides free healthcare for its citizens, it is well known that patients themselves also bear a part of the expenditure incurred for drugs and investigations. Therefore, the objectives of the study was to estimate the expenditure for drugs while being treated in a government hospital, to compare the personal and government expenditure on drugs and to analyse the cost according to different drug categories and number of days hospitalised.

\section{Methods}

The study was conducted in two phases due to the possible variation of drug availability in government hospitals. First phase was from May to June and second was from October to November in 2015. It was a descriptive cross-sectional study conducted using records of in-patients in a surgical unit, a medical unit and a pediatric unit in Teaching Hospital Karapitiya, Sri Lanka. Information about drugs used by patients was recorded from patients' bed head tickets. The Prices of drugs provided by hospital were taken from records in the indoor pharmacy of the hospital. Patients' personal expenditure on drugs was collected by interviewing patients and their close relatives. Costs of drugs were traced using payment bills and by obtaining price list from private pharmacies. The study was limited to the patients with a hospital stay between 3 to 10 days. Statistical analyses were performed using SPSS. The ethical approval for the study was obtained by the Ethical Review Committee, Faculty of Medicine, University of Ruhuna, Sri Lanka.

\section{Results}

The records of 66, 62 and 61 patients from medical, surgical and pediatric units respectively were used for the study.

\section{Estimation of average drug cost}

The average cost borne by the patient and the government for drugs in each unit studied are shown in table 1. Patients' expenditure on drugs is significantly higher than that of the government in all units $(\mathrm{p}<0.05)$.
The average drug costs borne by the patient and by the government were significantly different between pediatric and medical units $(p<0.05)$. The average drug costs borne by the patient and by the government were not significantly different between pediatric and surgical units as well as between medical and surgical units. Compared with other two units, the surgical unit showed the highest difference in drug expenditure between patient and government $(\mathrm{p}<0.05)$.

\section{Drug cost on various drug categories}

Drug expenditure was categorized according to the type of drug used (Table 2). The highest percentage was spent on antibiotics, both by the government $(74 \%)$ and the patients $(67.56 \%)$. The highest expenditure for antibiotics was recorded in the surgical unit and the lowest in the pediatric unit.

\section{Variations of drug cost with the duration of hospital stay}

Per day expenditure difference between patient and the government according to number of days hospitalised is shown in Figure 1. This per day expenditure difference increases significantly $(\mathrm{p}<$ 0.05 ) with the number of days hospitalised in surgical unit but not in other two units. Per day expenditure difference for antibiotics between patients and the government is also increased with the number of days hospitalised in the surgical unit but not the other two units. There is no such change in expenditure with the duration of hospitalisation for other type of drugs.

\section{Seasonal variation of antimicrobial drug cost}

The average patient antibiotic expenditure had decreased significantly (from Rs. 6,144.00 to Rs 4,577.00) while the government expenditure on antibiotics had increased significantly (from Rs. $1,640.00$ to Rs. 2,184.00) from first phase to the second phase of the study. Similar variation was not seen for other drug types. 
Table 1: The average drug cost by a patient and the government in pediatric, medical and surgical units

\begin{tabular}{llrl}
\hline Pediatric & Patient & $1,406.00$ & $71 \%$ \\
& Government & $5,48.00$ & $29 \%$ \\
\hline Medical & Patients & $3,204.00$ & $72 \%$ \\
& Government & $1,239.00$ & $28 \%$ \\
\hline Surgical & Patients & $3,678.00$ & $81 \%$ \\
& Government & 885.00 & $19 \%$ \\
\hline Total & Patients & $8,288.00$ & $76 \%$ \\
& Government & $2,672.50$ & $24 \%$ \\
\hline
\end{tabular}

Table 2: Average drug cost (Rs.) and percentages according to various drug categories in three units

\begin{tabular}{llrrrrrrr}
\hline & \multicolumn{1}{c}{ GIT } & Antibi. & Endo. & CNS & CVS & Nut. BI. & Respi. \\
\hline Paediatrics & Patient & 91.00 & 962.00 & 19.00 & 59.00 & 22.00 & 39.00 & 67.00 \\
& & $(7.23 \%)$ & $(76.40 \%)$ & $(1.50 \%)$ & $(4.68 \%)$ & $(1.74 \%)$ & $(3.09 \%)$ & $(5.32 \%)$ \\
& \multirow{2}{*}{ Govern } & 11.00 & 368.00 & 2.00 & 6.00 & 0.50 & 140.00 & 4.00 \\
& & $(2.07 \%)$ & $(69.23 \%)$ & $(0.37 \%)$ & $(1.13 \%)$ & $(0.09 \%)$ & $(26.34 \%)$ & $(0.75 \%)$ \\
\hline Medical & Patients & 122.00 & 2063.00 & 351.00 & 44.00 & 455.00 & 45.00 & 183.00 \\
& & $(3.74 \%)$ & $(63.22 \%)$ & $(10.76 \%)$ & $(1.35 \%)$ & $(13.94 \%)$ & $(1.38 \%)$ & $(5.61 \%)$ \\
& \multirow{2}{*}{ Govern } & 25.00 & 921.00 & 13.00 & 41.00 & 15.00 & 189.00 & 25.00 \\
& & $(2.03 \%)$ & $(74.94 \%)$ & $(1.06 \%)$ & $(3.34 \%)$ & $(1.22 \%)$ & $(15.38 \%)$ & $(2.03 \%)$ \\
\hline Surgical & Patients & 413.00 & 2464.00 & 303.00 & 229.00 & 148.00 & 13.00 & 32.00 \\
& & $(11.46 \%)$ & $(68.41 \%)$ & $(8.41 \%)$ & $(6.36 \%)$ & $(4.11 \%)$ & $(0.36 \%)$ & $(0.88 \%)$ \\
& \multirow{2}{*}{ Govern } & 29.00 & 657.00 & 8.00 & 20.00 & 7.00 & 146.00 & 2.00 \\
& & $(3.34 \%)$ & $(75.60 \%)$ & $(0.92 \%)$ & $(2.30 \%)$ & $(0.80 \%)$ & $(16.8 \%)$ & $(0.23 \%)$ \\
\hline
\end{tabular}

(GIT - cost for drugs related to GIT, Antibi - cost for Antibiotic drugs, Endo - cost for drug related to Endocrine system, CNS - cost of drugs related CNS, CVS - cost of drug related to CVS, Nut. Bl - cost for Nutrition and blood related product/drugs, Respi. - cost for drug related to Respiratory system)

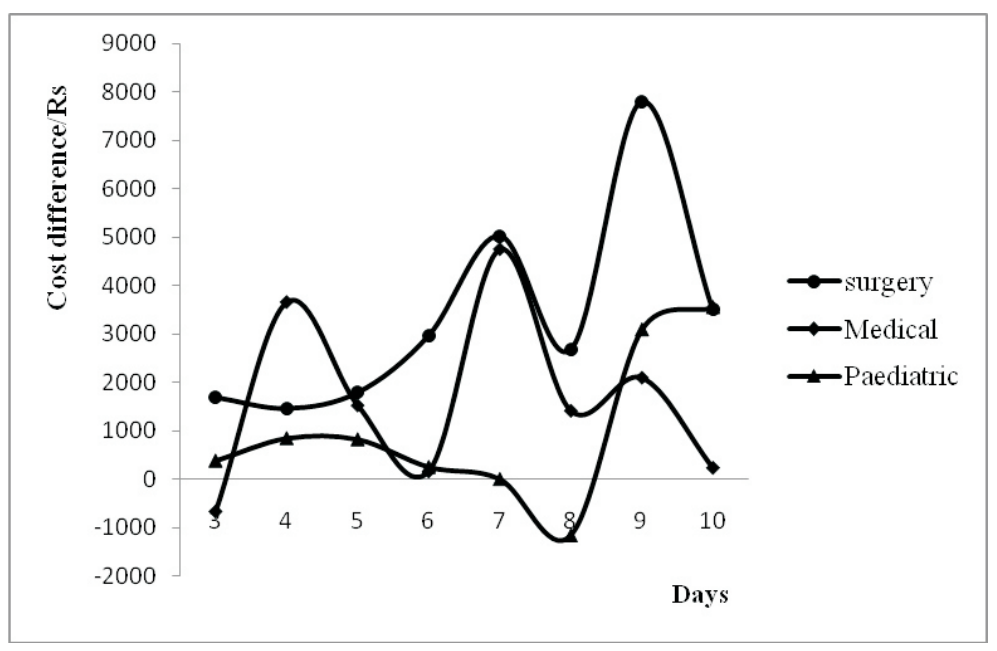

Figure 1: The variation of per day drug cost difference (cost borne by patient minus cost borne by government) with number of hospitalised days. 


\section{Discussion}

The present study indicates that the patients have to spend a considerable amount of money to purchase drugs during hospitalisation in a government hospital. The total drug expenditure borne by the patient is higher than that of the government. Several factors may have contributed to this. Unavailability of drugs in government hospitals, high price of the drugs when purchased from private pharmacies and usage of trade names in prescriptions can be contributory factors.

It is well known that drugs are often not available in government hospitals due to limited funds. Probably because of that, government provides limited number of drugs to particular unit even without paying much attention on the demand of that unit. This fact is exemplified by the finding that the government expenditure is lowest for the surgical unit (19\% Vs. $28 \%$ and $29 \%)$ which has highest total drug expenditure and highest patient expenditure.

The difference between patient and government expenditure increased significantly with the duration of hospital stay in the surgical unit compared to other units. Therefore patients have to bear higher cost if they stay for a longer period in the surgical unit compared to the other units. As stated above, patient's fraction of the drug cost is high in the surgical unit and it will be more with prolonged stay in the surgical unit due to the government being unable cover the drug expenditure. It indicates that the expenditure on drugs by the government is not on the demand of each unit but probably depends on limited fund availability.

This study shows that government spent considerably different amounts on antibiotics during two phases of the study. The discrepancy of availability of antibiotics in government hospital between two phases of the study can be one reason for this difference. This possibility is further strengthened with the fact that when antibiotic expenditure of the government is higher during the second phase of the study, probably due to the availability of them in government hospital, patient spent less. The possible variation of antibiotic availability in two phases suggests that government hospitals were unable to maintain continuous supply of antibiotics. Procedural disturbances in health ministry which are often highlighted in the mass media, can be one reason for this inability to maintain continues supply of some drugs (4).

The price of the medicines available in the local market was not regulated until new legislation was introduced in November 2016. The drug prices in private pharmacies are mainly determined by market forces and influenced by factors other than the production cost (5). When patients buy drugs from private pharmacies, they have to purchase them at a considerably higher cost. However, when health department purchases drugs through a tender procedure, low cost options are given the priority. Probably, that can be one reason for higher drug cost for the patients than the government.

The expenditure on antibiotics contributes considerably to the total expenditure on drugs for both patient and the government in all three units. More than $60 \%$ of total drug expenditure was on antibiotics by both the patient and by the government. Expenditure on antibiotics is proportionately higher in the surgical unit compared with other units. The cost difference between patient expenses and the government expenses is highest in the surgical unit and that is mainly due to high cost incurred on antibiotic purchasing in the surgical unit. Increase of expenditure by patient with the duration of stay is also considerably higher in the surgical unit compared to other two units and this is mainly due to increased expenditure on antibiotics. This reflects the frequent use of costly antibiotics to the patient which is questionable most of the time (6-8).

The other possible contributory factor for higher drug expenditure by the patients is usage of trade names when prescribing. Even though not studied extensively in the current study, most of drugs prescribed to buy from outside pharmacy are in brand names. This totally depends on prescribers' interest on brand names. It is a well-known fact that branded drugs are expensive than generic drugs in Sri Lankan market (9). Hence, expenditure incurred by patient is higher than that by the government in case of the same drug. But, whether this high expenditure on branded drugs is really beneficial for patient or not is controversial question(10). 


\section{Conclusions}

Patients' expenditure on drugs is higher than that of government in all three units. Comparing all drugs, expenditure on antibiotics is the highest from the patient as well as from the government. Surgical unit has the highest difference of drug expenditure between patient and government compared to other two units and this discrepancy is increased with the number of days hospitalised.

\section{Conflicts of interest}

There are no conflicts of interest disclosed.

Source(s) of support - None

\section{References}

1. Alwis D, Sanil S. Sri Lanka Health Accounts: National Health Expenditure. 2011, Institute for Health Policy.

2. Global health expenditure database, WHO, Editor. 2014.

3. Gunatilleke, N., Health sector allocated Rs. 216/- bn from budget, in Daily News. 2016 March.
4. Dissanayake C. Fazlulhaq N. Drug shortage makes mockery of 'free health', in The Sunday Times. 2015 March.

5. William S. Comanor and SO Schweitzer, Determinants of drug prices and expenditures. Managerial and Decision Economics, 2007; 28(4-5): 357.

6. Arsp Working Group, T.S.L. C.o. M. A multi centre laboratory study of Gram negative bacterial blood stream infections in Sri Lanka. Ceylon Med J, 2013; 58(2): 56-61.

7. WHO, Regional Strategy on Prevention and Containment of Antimicrobial Resistance. 2010, World Health Organization, Regional Office for South-East Asia.

8. Song, J.H., et al., High prevalence of antimicrobial resistance among clinical Streptococcus pneumoniae isolates in Asia (an ANSORP study). Antimicrob Agents Chemother, 2004; 48(6): 2101-7.

9. Jayasinghe $\mathrm{S}$, Jayasinghe $\mathrm{S}$, de Silva P. State can make drugs available cheaply to poor people. BMJ, 2003 March 8; 326(7388): 553. PMID: 12623926.

10. Werasuriya K. Some aspects of pharmaceuticals in Sri Lanka. Economic Review, 1991 April; 13. 